\title{
A NEW APPROACH TO TEACHING INTRODUCTORY COMPUTING AND INFORMATION TECHNOLOGY BY DISTANCE LEARNING - ADDRESSING KEY ISSUES
}

\author{
Elaine Thomas, The Open University, United Kingdom
}

\section{Abstract}

New introductory level 1 curriculum has been developed for the open-entry Computing and information technology (IT) degree programme in the School of Computing and Communications in the Open University (OU UK). Three key issues in Computing and IT teaching had been identified, namely: student retention, declining participation by women in Computing and IT modules, and the teaching of introductory programming at level 1. Dealing with these issues formed part of the rationale for developing the new curriculum. Computing and IT students at the OU are part-time distance learners and there is a diverse student population with a range of learning needs. Two-thirds of students are in employment, so it is important their work-life balance is considered in the design of new curriculum.

Retention of students is an important issue in distance education (Simpson, 2012) as dropout rates are high. Students study the new level 1 course "TM111 Introduction to Computing and Information Technology 1" first followed by "TM112 Introduction to Computing and Information Technology 2". Both module production teams engaged in a learning design process to assist with the management of student workload and to ensure coherence and consistency across both modules. The declining rate of participation by women in Computing and IT is a source of concern across both the employment and the higher education sectors (BCS, 2016). In developing TM111 care was taken in the selection of examples and images to ensure that female Computer Scientists were adequately represented so as to provide suitable role models for female students (Frieze \& Quesenberry, 2019). Students often struggle with computer programming but easing "cognitive load" (Sweller, 1988) may be helpful, especially in a distance learning context. TM111 uses its own customised version of Scratch, called OUBuild, to assist students in acquiring foundational programming skills. TM111 is presented using a blend of traditional print materials plus online learning and also specialised software. The module is designed to appeal to a wide range of students with a variety of study intentions and learning needs, many of whom have few formal qualifications (or none at all).

TM111 has proven to be very attractive to students and participation by female students has increased to $24 \%$, at least four percentage points over the previous module. Student responses to the module as a whole and the teaching on programming has been positive overall. More 
work is needed to evaluate the impact of the new modules in equipping students with the necessary programming skills to succeed with programming at level 2.

\section{Introduction}

This paper discusses the design and development of a new level 1 course, "TM111 Introduction to Computing and Information Technology 1" which was first presented by the School of Computing and Communications of the Open University (OU UK) in autumn 2017. The rationale for developing the new curriculum is explained and also the measures that the module production team used to address key issues in our level 1 undergraduate Computing and IT programme which are: retention of students in level 1; recruitment and retention of female students to Computing and IT modules, and equipping students with the necessary programming skills to succeed with programming at level 2. Engaging in a learning design process assisted with the management of student workload - an important factor in student retention. The structure and content of the module including the assessment methods are described. Finally, the students' reception of the first presentation in October 2017 will be briefly reported.

\section{Rationale}

Major aims of developing the new curriculum were (a) to improve general completion and progression rates in our Computing and IT level 1 modules (b) to address and increasing imbalance between male and female students in our Computing and IT modules (c) to improve skills development, particularly in the area of coding and software development, but also to develop general study competences (Havergal, 2015).

\section{Retention and progression}

Our "open" mission means that the OU(UK) does not require entrance qualifications so the University provides for a diverse range of students with a range of learning needs. Around $40 \%$ of students studying introductory Computing and IT modules with the OU(UK) have lower than A level qualifications or none at all. Most of our students are mature students and only around $11 \%$ of those studying level 1 Computing and IT modules are under 21 years of age. Two-thirds of our students are in employment, but a key motivation for studying is to advance or change their career. Student drop-out is a major problem in distance education which Simpson (2012) has labelled the "distance education deficit" and argues that it is important to strengthen students' learning motivation and their resilience. The "growth mindset" theory (Dweck, 2015) suggests that being able to try new strategies and cope with setbacks are very important. The OU(UK) surveys students who drop out of its modules and a common response is that an unexpected work or family issue has resulted in the student falling behind with their studies. Student workload is recognised as an important issue in student retention (Whitelock et al., 2015). It is important to recognise the student's work-life balance whilst ensuring the modules meet the required learning outcomes. 


\section{A New Approach to Teaching Introductory Computing and Information Technology by Distance Learning - Addressing Key Issues \\ Elaine Thomas}

\section{Attracting women students}

At a time when the Computing and IT jobs market is growly strongly, the declining participation rates of women is a source of concern across the sector. Women account for $56 \%$ of all higher education graduates, but only $17 \%$ of graduates in IT related subjects are women. Only $15 \%$ of applicants to Computer Science courses in higher education were female, according to the "Women in IT Scorecard" (BCS, 2016). Participation by female students in the OU(UK)'s level 1 Computing and IT introductory modules had declined from around $33 \%$ fifteen years ago to under $20 \%$ in more recent times. Cross-cultural studies indicate differences between cultures and countries, for example, India has equal representation between men and women entering careers in Computing and IT (Sondhi, Raghuram, \& Herman, 2018). Also, Frieze and Quesenberry (2019) report studies in the US showing that the curriculum was not the cause of the problem, and that cultural differences rather than gender differences were important in attracting and retaining female students. For example, providing female role models greatly improved participation by women students.

\section{introductory programming}

Students often find programming difficult and they can easily lose motivation. There is an ongoing debate about the most effective way to teach programming, especially as skills and understanding of one programming language does not necessarily transfer easily into other programming situations. Cognitive Load Theory (CLT) (Sweller, 1988) which focuses on the structure and limitations of the working memory provides a useful explanation of why some subjects are difficult to learn. Struggling with syntax in a text-based programming language is particularly difficult and frustrating for novice programmers in a distance learning context. The intrinsic factors (Sweller et al., 1998) in computer programming involve interaction between the syntax of a particular programming language and programming concepts, such as loops, variables etc. Jenkins (2002) argues that it is the blend of learning types required: surface learning for remembering features such as syntax and order of precedence, and deep learning in the understanding of concepts and development of true competence, makes programming difficult. Using a visual programming environment, such as Scratch avoids this problem.

The predecessor module, "TU100 My digital life", used "Sense", which is a visual programming environment specially adapted from Scratch (n.d), to provide a "gentle" introduction to programming skills for our extremely diverse student cohorts. The programming teaching was introduced early in the module, but programming activities were woven through the study material across the whole module, although they formed only one aspect of the overall study. Our research suggested that Sense had been far more successful in engaging students in programming than the textual language used in a previous level 1 module (Thomas et al., 2018). However, feedback from some students in the University's SEaM (Student Experience on a Module) survey suggested that (a) learning programming alongside other topics was confusing for novice students and (b) studying an introductory 
programming language across a 30-week module was too long for students with prior experience of programming. In addition, there were concerns that students were not being sufficiently well-prepared for study at level 2 in terms of understanding problem-solving and heuristics.

\section{Designing the module}

The existing 60 credit module was redesigned as two 30 credit modules "TM111 Introduction to Computing and Information Technology 1" and "TM112 Introduction to Computing and Information Technology 2". Both modules consist of 21 weeks (approximately 14 hours of student workload per week) and are presented in October and April. Students start with TM111 and progress to TM112 on successful completion and pass of TM111.

Early in the production process the teams of academics developing the two modules engaged in a learning design process together. The term learning design refers to the educational processes involved in teaching and learning to ensure that the time that students spend studying is as productive and effective as possible (Whitelock et al., 2015). We discussed our ideas for the content and design of each module to ensure consistency across the modules and to avoid duplication of topics in a learning design workshop. A central part of the learning design process is the use of an activity planner which is a graphical online tool that captures descriptions of student activity and also the amount of time that we expect students to spend on each activity. The planner aids the module teams in separating out the teaching and learning involved and in mapping this onto a learning activities taxonomy (Conole et al., 2004), i.e. categorising the activities as: Assimilative; Finding and handling information; Communication; Productive; Experiential, and Adaptive/Interactive.

Figure 1 shows the first draft of the activity planner for TM111 with the first three study weeks of study completed. At an advanced stage in the production process, a member of staff who was not involved in production, worked though the materials and completed the workload planning section of the activity planner to ensure that the workload was balanced across the module. 


\section{A New Approach to Teaching Introductory Computing and Information Technology by Distance Learning - Addressing Key Issues \\ Elaine Thomas}

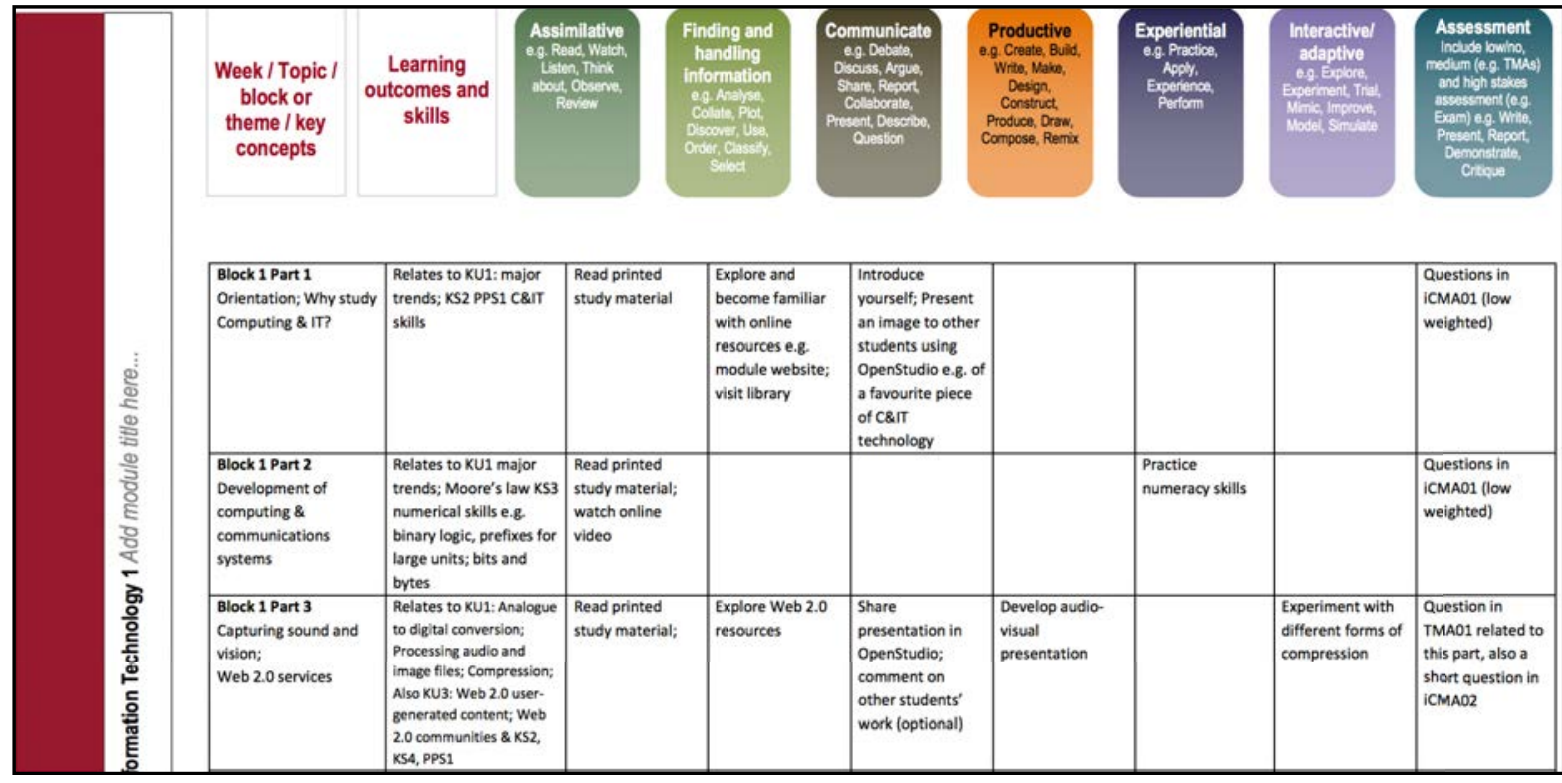

Figure 1. The first draft of the TM111 activity planner for weeks 1-3

\section{Module design and content}

There are three blocks of study in TM111, each block consists of six Parts and covers six weeks of study, followed by a week for completing an assessment. Most of the materials are in print but guided by an online study calendar and supported by online materials, online audiovisual resources, and module forums. Full consideration was given to the cognitive load imposed by the instructional design itself (Sweller et al., 1998) in the development of the TM111 study materials. Tight control was kept over the wordcount and workload of each Part during production. The programming in TM111 is designed to be covered in one block of study (100 hours) over a period of six weeks with a seventh week allocated for completing the programming assessment. The intention is to reduce cognitive load by allowing students to focus on learning to program and closely-related concepts and skills i.e. developing simple algorithms, problem-solving and testing and debugging of programs.

\section{Block 1: The digital world}

The workload for Block 1 takes account of the "distance learning deficit" (Simpson, 2012) in that time is allocated in the first two weeks to allow students to find their way around University systems. This is especially important as many students are new to the University. Block 1 commences with the student's own experience of using computing and IT systems, covering a range of topics. Students explore how computers and networks developed; how analogue images and sounds are converted into digital formats; and how data is stored and managed in databases (including big data). They also gain practical experience of constructing webpages, and, in the final week, they consider how interfaces help us to interact with computers successfully. Positive role models of women in computer science (Raghuram et al., 2018; Frieze \& Quesenberry, 2019) are well represented in the materials e.g. a photograph of Grace Hopper (the inventor of the COBOL programming language) standing 
beside a 1950s computer was chosen to illustrate the development of computers in Part 2 to show that women used to be well represented in computer science in the past.

\section{Block 2: Creating solutions}

We chose the title of Block 2 "Creating solutions" to encourage the idea that programming is about being creative in solving problems. The idea was that we should attempt to appeal to a diverse range of students which would have the effect of improving participation by women. After careful consideration, we opted to use the visual programming approach on TM111 developing OUBuild (2017) from the open source version of Scratch 2.0 (n.d.). In addition to providing an appropriate introduction to programming skills, this promotes engagement with programming at level 1 (Thomas et al., 2018) and also helps to raise students' awareness of the strengths and weaknesses of different types of programming. Students explore a variety of programming techniques, such as sequencing, iteration and selection and are encouraged to be creative in developing simple animations and simulations. They create programs involving animation, sounds, numbers and text. Students are also taught how to test and debug their programs. The activities highlight enjoyment in programming, whilst developing the foundational skills and knowledge necessary for university study. The block ends by exploring algorithms, what they actually are, and considers some of their strengths and weaknesses.

\section{Block 3: Connecting people, places and things}

In the final block students are introduced to communication networks, including the structure and operation of the internet, and wired and wireless systems. The first three parts of the block explore transmission media, the electromagnetic spectrum, the structure and operation of the internet, and introduces wireless communication. Students gain an understanding of different types of wireless communication including mobile telephony, WiFi, Bluetooth, ZigBee and RFID. The final three parts discuss the Internet of Things (IoT), on-line communication, and issues of security, gender, health care, democracy, and the "digital divide" in ICT. The material on IoT covers topics such as home automation (including coping with signal obstructions), energy harvesting, low-power WANs, and the future of the IoT. The Online Communication's part explores a wide range of asynchronous and synchronous activities, such as forums, group communications, online communities. The important issues relating to social networking are discussed, such as privacy and safety, along with concepts of social presence and awareness. The final part, "The networked society", addresses the use of networked computer systems by government and the health service including biometrics and DNA information. Audio interviews are included with three researchers who have investigated the impact of mobile phone use on the lives of socially excluded young women.

Throughout all three blocks of the module, students develop skills in communication, numeracy, digital and information literacy (DIL) and employability as well as their study skills which are so important for their undergraduate work (Havergal, 2015). 


\section{A New Approach to Teaching Introductory Computing and Information Technology by Distance Learning - Addressing Key Issues \\ Elaine Thomas}

Students study in tutor groups of around 20 students run by associate lecturers. Although distance learning tends to be a rather solitary pursuit, the module team aims to create a strong sense of a learning community through the use of online asynchronous communication tools, such as forums, blogs and wikis are used for communication between students and their peers, their tutors and the module team. Creating a sense of community is particularly important in Block 2 where there are specific online activities to support the teaching of programming and problem-solving.

\section{Assessment}

The module uses continuous assessment which consists of three interactive computer-marked assignments, iCMAs and three tutor-marked assignments (TMAs) marked by associate lecturers. The iCMAs consist mainly of short-answer and multiple-choice questions to check knowledge and understanding. The cut-off date for the first iCMA (iCMA41) occurs early in the module, to ensure that students are engaging with the module in the early stages. Advice can be provided if students do not submit or perform poorly in the first iCMA. The second and third iCMAs are scheduled midway through blocks 2 and 3 respectively. Assignment iCMA42 tests numeracy, problem-solving and programming, and iCMA03 further tests knowledge of networks and numeracy associated with networks. The TMAs occur at the end of each block of study and assess the content covered in the block. The TMAs provide an opportunity for personalised tutor feedback and assist a student's progression to the following module, TM112. Tutors are encouraged to promote a "growth mindset" (Dweck, 2015) in their feedback on assessments to encourage students to experiment and learn from their mistakes, particularly in programming. For most students, this module will be followed by "TM112 Introduction to Computing and Information Technology 2". This module uses Python (Keopke, 2010), to broaden and deepen students' understanding of coding, algorithmic thinking and problem-solving. (For further details on the teaching of programming in TM112 see Piwek et al., 2019).

\section{Reception by students and pass rates}

TM111 recruited over 2,500 students, more than expected, of these $67 \%$ were new students. Female students accounted for $24 \%$ of the total number, which is $4-5$ percentage points more than the previous module. Retention and pass rates were also higher than other 30 credit level 1 modules in Computing and IT.

The results of the student satisfaction survey (SEaM) at the end of the module were very positive with $91.9 \%$ of respondents agreeing that they would be happy to recommend OU study to other students, suggesting that they were satisfied with the module. The module team were particularly concerned about how students would receive the programming in OUBuild. A sample of the open text comments from the SEaM survey is shown in Table 1. The comments from students $\mathrm{A}$ and $\mathrm{B}$ are more representative of student feedback which suggests that using OUBuild has been successful. Student C's comment suggests that they 
were not convinced about OUBuild, but this was not typical of the cohort, and the student will progress to using Python on the next module.

Table 1: $\quad$ A sample of responses in the SEaM survey

\begin{tabular}{ll}
\hline Student & Response \\
\hline A & $\begin{array}{l}\text { I have really enjoyed the challenge of my first OU module. It has been hard work but it is } \\
\text { great to be learning and the online student forums mean you are never alone and if you } \\
\text { get stuck there is always someone ready and able to help. }\end{array}$ \\
B $\quad \begin{array}{l}\text { lenjoyed study this module very much. The best part for me was Block } 2 \text { as I am } \\
\text { interested in programming. It was great to start Programming with OU Build because it }\end{array}$ \\
helped me to learn basic programming skills. \\
C $\quad \begin{array}{l}\text { I didn't really enjoy OU Build but that could just be me, it didn't feel like I was learning } \\
\text { anything meaningful and would have preferred to have gone straight into simple source } \\
\text { programming. The math exercises I found very interesting and informative. }\end{array}$
\end{tabular}

\section{Conclusion and further work}

The new OU(UK) module "TM111 Introduction to Computing and Information Technology 1 " adopts a very broad approach to the introduction of foundational Computing and IT knowledge and skills to take account of the learning needs of a diverse cohort of students. The module addresses key issues in education namely: student retention; recruitment of female students and the teaching of programming to novice students. The teaching and learning materials include a coverage of theory, technology, practical skills development, and the wider socio-technological issues in the Computing and IT field. Traditionally, students have found many of these concepts, particularly programming and mathematical topics, problematic, so great care has been taken with student workload, the mix of study materials (print, online resources, and a file-sharing environment), the choice of programming environment and to the staged development of skills throughout the course. Although TM111 has been wellreceived by students (and TM112 also) to date, more work is planned to evaluate the impact of the design of the new curriculum on students' performance in programming at level 2. Further research will involve tracking new students from TM111 and TM112 through onto second level programming modules.

\section{References}

BCS (2018). Women in IT Scorecard: A definitive up-to-date evidence base of data and commentary on women in IT employment and education. BCS, The Chartered Institute for IT and the Tech Partnership. Retrieved from https://www.bcs.org/upload/pdf/womenscorecard-2016.pdf

Bissell, C. (2017). A new approach to the introductory teaching of Computing and IT at the Open University UK. In J. Domenech i Soria, V. Vela, M. de la Poza, \& B. Desamparados (Eds.), Proceedings of the HEAd'17. $3^{\text {rd }}$ International Conference on Higher Education Advances, Universitat Politècnica de València, València, 101-108.

Conole, G., Dyke, M., Oliver, M., \& Seale, J. (2004). Mapping pedagogy and tools for effective learning design. Computers and Education, 43, 17-33. 


\section{A New Approach to Teaching Introductory Computing and Information Technology by Distance Learning - Addressing Key Issues \\ Elaine Thomas}

Dweck, C.S. (2015). Growth. British Journal of Educational Psychology, 85(2), 242-245.

Frieze, C., \& Quesenberry, J. L. (2019). How Computer Science at CMU Is Attracting and Retaining Women. Communications of the ACM, 62(2), 23-26. Retrieved from https://cacm.acm.org/magazines/2019/2/234346-how-computer-science-at-cmu-isattracting-and-retaining-women/fulltext?otl

Havergal, C. (2015, December 10). UK Engagement Survey: universities have limited impact on students' 'soft' skill development. Times Higher Education [Blog post]. Retrieved from https://www.timeshighereducation.com/news/uk-engagement-survey-universities-havelimited-impact-students-soft-skill-development

Jenkins, T. (2002). On the Difficulty of Learning to Program. Proceedings of the $3^{\text {rd }}$ Annual HEA Conference for the ICS Learning and Teaching Support Network, 1-8.

Koepke, H. (2010). Ten reasons Python rocks for research (and a few reasons it doesn't). Retrieved from https://www.stat.washington.edu/ hoytak/blog/whypython.html

OUBuild (Software) (2017). The Open University. Retrieved from https://bitbucket.org/lts$\mathrm{imd} /$ public-tm111

Piwek, P., Wermelinger, M., Laney, R., \& Walker, R. (2019). Learning to program: from problems to code. Paper presented at the Third Conference in Computing Education Practice (CEP), Association for Computing Machinery (ACM), Durham, United Kingdom. Retrieved from http://oro.open.ac.uk/58202/

Raghuram, P., Herman, C., Ruiz B. E., \& Sondhi, G. (2018). Women and IT Scorecard - India 2018. The Open University. Retrieved from http://gsmit.com/userassets/Publications/GSM-IT_SCORECARD-INDIA_2018_Final.pdf

Scratch 2.0 (Software) (n.d). MIT Media Lab. Retrieved from http://scratch.mit.edu

Simpson, O. (2012). Supporting Students for Success in Online and Distance Learning (3 ${ }^{\text {rd }}$ ed.). London: Routledge.

Sweller, J. (1988). Cognitive load during problem-solving: Effects on learning. Cognitive Science, 12(2), 257-28.

Sweller, J., van Merriënboer, J., \& Paas, F. (1998). Cognitive architecture and instructional design. Educational Psychology Review, 10(3), 251-296. doi:10.1023/A:1022193728205

Thomas, E., Kouadri Mostéfaoui, S., \& Jefferis, H. (2018). Visualising the code: a study of student engagement with programming in a distance learning context. In M. Bajić, D. N. Dohn, M. de Laat, P. Jandrić, \& T. Ryberg, (Eds.), Proceedings of the $11^{\text {th }}$ International Conference on Networked Learning 2018 (pp. 140-148). Springer. Retrieved from https://www.networkedlearningconference.org.uk/abstracts/thomas.html

Whitelock, D., Thorpe, M., \& Galley, R. (2015). Student workload: a case study of its significance, evaluation and management at the Open University. Distance Education, 36(2), 161-176, doi: 10.1080/01587919.2015.1055059. 